\title{
Thai Contemporary Dance
}

\author{
Suphannee Boonpeng ${ }^{1}$, Surapone Virulrak ${ }^{2} \&$ Wutthipong Roadkhasemsri ${ }^{1}$ \\ ${ }^{1}$ Faculty of Fine and Applied Arts, Mahasarakham University, Khamriang Sub-District, Kantarawichai District, \\ Maha Sarakham Province, Thailand \\ ${ }^{2}$ 35/160 Noble House Phyathai, Phyathai Road, Ratchathevi, Bangkok, Thailand \\ Correspondence: Suphannee Boonpeng, 376/170 Salintara 30 BW, Rama 3 Road, Bangklo, Bangkolaem, \\ Bangkok 10120, Thailand. E-mail: obbonearth@gmail.com
}

Received: June 29, 2013 Accepted: August 7, 2013 Online Published: October 29, 2013

doi:10.5539/ass.v9n15p172 URL: http://dx.doi.org/ass.v9n15p172

\begin{abstract}
Thai contemporary dance is the fusion of various dance forms and has evolved in Thai society in accordance with Western influences on Thai culture. This qualitative research examines the background, style and form of contemporary dance in Thailand in order to determine a model for future creation of dance. The investigation identifies four distinct periods in the history of Thai contemporary dance that have seen three clear style concepts emerge: dance based on popular literature, dance based on social experience and original artistic creations. There are four steps in dance creation that influence the overall choreographic creation, which are input, process, output and outcome. Thai contemporary dance depends on social conditions, the economy, politics and industry, as well as the important factors of choreographer, audience and inheritor. This research concludes that, for successful construction of Thai contemporary dance in the future, the choreographers must constantly invent, develop or establish quality individual creative concepts and methods that can be used to attract the interest of an ever-changing audience.
\end{abstract}

Keywords: choreography, dance, reconstruction, contemporary, Thai identity

\section{Introduction}

Contemporary Dance in Thailand dates back more than 60 years. Although the form and background of Thai Contemporary Dance is now starting to be discussed, there is little formal information available other than some old documents and photographs. As a result, there has been little information available to analyze the impact of various dance forms, especially Western Modern Dance and Western Ballet, which are viewed as being the most important influencers on the evolution of contemporary dance in Thailand.

Dance in Thailand from the past to the present day has been a form of presenting the creative results of dance that depicts Thai identity. Nowadays, this is the most popular form of dance in modern organized performances. It is common among the new generations for Thai dance to be perceived as slow, long and repetitive with movements and postures that are similar, even though new performances are frequently created. This is because the same basic dance movements are used to produce performances to new music and no new postures are created. Thus, Thai dance may seem unchanging in comparison to the short-term, hurried nature of global society that expresses emotions and requirements. However, Thai dance remains a valuable and beautiful national treasure for descendants to conserve.

Dances as culturally structured movement systems are social and cultural constructs that exist in memory. These systems are recalled as movement motifs, imagery and as systems, and are used to create compositions that produce social and cultural meaning in performance. Performance is a cultural practice of representation. Cultural practice and its representation inevitably enter the realms of ideology, politics, beliefs, ethnicity, traditions and many others (Nor, 2003, p.3).

Practice and performance of Thai dance, including its rules and many conventions are important characteristics of art that fit with established attitudes, beliefs and expression of different customs. These must be conserved by the new generation of Thai dancers, only a few of whom truly understand its value and importance of practice according to rules and strict regulations. This lack of realization causes a scarcity of standard performances that are accepted in each region, especially when considering the changing requirements of audiences, who are only able to watch the same performances. The audiences and those presenting the art thus need new styles that are 
entertaining and attract interest. These styles must yet retain the essence of Thai artistic and cultural identity for the benefit of tourism and commerce, which will cause the creation of new Thai contemporary dance pieces in order to increase the options of modern day audiences. Choreography is the process of selecting and forming movement into a dance and designing the action to satisfy a particular intent (Cheney, 1989, p.83). The creation of dance has the characteristics of including all different forms of choreography, mixing Thai dance, choreography from other schools and other forms of art, such as drama, poetry readings, drawing, art including projections, acting, techniques using color, light and sound and the use of higher technology.

Although Western dance and Western contemporary dance have an important influence on Thai contemporary dance, Thai dancers are able to select various Western techniques according to the suitability and imaginative composition in order to integrate with Thai existence. This is achieved by the creation of dance using experience in selection of elements that are part of Thai identity and the choreographer's individuality from the past to the present. Even though different periods will reveal different styles of contemporary dance, choreography leaders remain, who will create pieces using the same original techniques. Current trends of Thai contemporary dance design and development are independent and more disconnected from the tradition methods. This is caused by modern Thai dancers and the increased fame of the dance in the last sixty years, which has made Thai people understand and accept the dance even more. Also, the evolution of information and communication has enabled people to access and watch the uniqueness of distant cultures and communities. Additionally, Thai choreographers and technicians have improved their skill and creativity, increasing the potential of their work to meet the design visions and have an equivalent quality to the work of foreigners. However created, the choreography has value for Thai society and identity, which is the creation of dance that takes characteristics of art culture and national custom to be part of the performance, regardless of technique and method. Dances are created and received in relation to the conventions and traditions of a particular time and place. Therefore, the understanding of a dance relies upon knowledge derived from four sources and they are the socio-cultural background, the context, the genre and style and the subject matter of the dance (Adshead, Briginshaw, Hodgens \& Huxley, 1988, p.65).

Work that reveals Thai identity and culture often receives more respect, praise and acceptance from the audience than work that reveals aspects of other nations. This includes respect, praise and acceptance from critics, artists and the media, both domestically and internationally. Work containing culture and identity from other nations is less well received because it is not Thai; the choreographers are accused of forgetting their roots and of being negligent to Thai dance. In the creation of dance in modern society, the choreographer must be aware of customs and traditions that Thai society and its people respect, including the nation, religion, the Great King and teachers, both living and deceased. For example, Thai tradition requires that nothing can be raised above the head of the image of the King and our King cannot be dishonored. The western choreographer could find this situation as the sharp edge of the creative cross-cultural process (Nagavajara \& Lake, 2005, p.113). These are affronts that cannot be accepted by Thai society. This research, Thai contemporary dance, thus compares studies in order to conclude a design method and process for creating Thai dance that is valuable and beautiful. This method should conserve Thai art culture so that it reflects Thai identity in the correct form and is suitable for modern Thai society.

\section{Research Objectives}

For this investigation, the researchers aimed to explore the basic concepts and strategies in the creation of dance choreography for Thai contemporary dance that mixes the design innovations of Thai dance and design innovations of other dance schools or other performance arts. The research aimed at finding data within domestic and foreign documents from the past and the present, but data analysis was focused on finding basic concepts and theories related to present day dance posture and movement design in Thailand for the year 2011. The ultimate aim was to identify a model for future creation of dance that mixes Thai style and the styles of other schools or performance arts.

\section{Research Methodology}

\subsection{Research Area}

The researchers selected the study from the results of five Thai contemporary dance choreographers. These five people were Vararom Pachimsawat from The Company of Performing Artists, Narapong Charassri from Thai Art Movement, Manop Meejamrat from Pattarawadee Theater, Pichet Klunchun from the Pichet Klunchun Dance Company and Thongchai Hannarong from Gomonlagoon. The research concepts included the use of founding principles of contemporary art, theories of choreography and the birth, development and existence of 
contemporary Thai dance. This investigation combined historical study and qualitative research techniques. The research began in July 2010 and was concluded in February 2013.

\subsection{Research Steps}

In order to ensure that research and analysis was thorough, the researchers followed a ten-point plan of data organization. The ten stages can be summarized as follows: a) selection of the research topic, so to define the limits of the investigation; b) review of literature and related documents, so to become fully acquainted with the historiography surrounding the research material; c) formulation of a research problem; d) formulation of a research hypothesis; e) source consideration; f) formulation of research instruments; g) data collection; h) scrutiny and analysis of data, including classification of data in accordance with the research objectives to make analysis more convenient; i) data interpretation; j) research report and publication.

\subsection{Research Tools}

Research tools for this investigation were composed of evidence from various sources, including scholarly articles, performance programs, photographs, performance recordings, interviews, focus group discussions, and observation. Documentary investigation was conducted from scholarly books about dance, research reports and theses on dance, as well as performance photographs. Interviews with dancers, performers, choreographers and audience members were undertaken using individual interview technique, group interview technique, telephone interview, online social network interview, observation and participation in performance programs, including academic seminars on dance and contemporary art, dance rehearsals, viewing of live performance and recordings, performance experience and creative work of the researchers. Further documentary research was conducted using research documents, books and articles related to theories of choreography; various aspects of dance performance creation, such as postures and movement; performance design theories and management of design components, costume, music and performers; research documents related to the history and evolution of dance, Thai music, Western music and contemporary music used in dance performances; research documents related to various aspects of performance design, such as stage, costume and decoration, make-up and hair for the performance and theories of color and lighting. In addition, the research team utilized various online and printed publications related to performance management; Thai culture and identity; ASEAN dance; concepts and theories of aesthetic art, art and contemporary art critiques; general humanities, research autobiographies; articles, documents and general information of Thai performance artists and choreographers. As part of the primary research, the researchers interviewed dance performers, choreographers (those from the case studies and others), and experts in Thai dance, Lanna dance and contemporary dance, as well as music and art composers for contemporary dance performance and audiences in Bangkok, Chiang Mai Province and Ratchaburi Province. Observation entailed viewing various Thai contemporary dance performances, music performances and contemporary Lanna dance performances, musical dramas, stage dramas and other live performances. Recorded performances were also viewed from DVDs and the Internet. The researchers attended academic meetings related to dance and contemporary dance in Bangkok and Maha Sarakham Province in Thailand, Malaysia, India, Hong Kong and academic meetings concerning contemporary art in Bangkok and Phitsanulok Province in Thailand.

The researchers organized a knowledge share program (for the Chulalongkorn University 100 year anniversary), of which one part was a practical seminar in the creative design and production of dance performance and contemporary dance performance. This integrated fine and applied arts and adopted the process of creative design that used the concepts of contemporary society. The researchers invited three creative artists as experts in Thai contemporary dance, who were also winners of the Silpathorn award (Prasarttong, Meejamrat \& Klunchun). This program enabled the researchers to study the characteristics of concepts and thought and work processes and their transmission among the program participants. The outcome of the program allowed the researchers to clearly understand the similarities and differences between the three individuals regarding Thai contemporary dance and analyze the answers and concepts of choreography in Thai contemporary dance performance.

The researchers could thus develop a creative design model from the sample artists by separating the data into nine categories: a) concepts of inspiration or muses and plot; b) story or part of literature that is performed; c) basic design; d) costume and decoration; e) musical components; f) dance postures and movement; g) performers; h) performer roles; i) creative performance style. These categories were also formed through the reasons of the research hypothesis that the background of the art is one important factor in creative design, in all characteristics that are similar and different. Thus, the researchers collected related data in an artist-specific table under headings following a number of criteria, namely hometown, family status, education, gender, marital status, 
performance style, training, performance experience, creative design product, financial scholarship, previous affiliations, affiliations founded by the artist and performance product.

\section{Research Results}

Art that reveals international roots or mixtures was first seen in Thailand when the country had contact with other nations. This has been visible since the period of King Rama IV in architecture, temples, education and dress, including various aspects of lifestyle that have an effect on everyday life and maintenance of Thai identity. Thailand has received international influences continuously from this period until the present day. For there to be actual benefit of using international concepts, Thai identity must be incorporated, no matter what that knowledge is used for, where, by whom and to what extent.

\subsection{Phenomenon of Contemporary Thai Dance}

The analysis of data collected led the researchers to discover that Thai contemporary dance has been performed one-hundred and ninety-nine times from 1947 until the present day (2011), telling one-hundred and sixty three stories. There have been forty-four choreographers and Thai contemporary dance choreographers, twenty-two individual females, twenty-one individual males and one group. Thirty-four of the choreographers were Thai nationals and a further nine were foreign nationals, with the choreographers of two stories of unknown origin.

There were found to be four distinctive periods of Thai contemporary dance.

\subsubsection{Period 1: The Introduction of Western Dance from 1947 to 1961}

Thai dance and drama were influenced by western dance for the first time during this period. The choreographers had creative ideas to improve, modify and mix postures or movement characteristics of the Thai dancers with postures and movements from other conventions and schools. This was in order to create postures and movements that were new, different and unusual. The performances had many different acts and were similar to the performance of Jintaleela. Important artists of the time were Thanpuying Paew Sanithwongseni and Lamul Yamakup.

\subsubsection{Period 2: Adapted Thai Ballet from 1962 to 1986}

Performances combined Western ballet and Thai dance in the areas of costume, clear dance techniques and creation of new dances using Eastern and Western art. This saw the creation of performances with a new style and was known as applied Thai ballet. The important people of this period were King Bhumibol Adulyadej and his wife Queen Sirikit. Their Majesties supported the combination of Thai classical dance and ballet, notably in the performance of the Manohra Ballet. This ballet used the King's composition as its musical score, while the King designed and supervised the production of the performance background. The important artists of the time were Khunying Genevieve Lespagnole Demon, Warawut Sumavong, Varaporn Pramoj, Temdeun Kesakomol, Pornpimol Kanthatham, M. L. Suchira Visitkul, Surapone Virulrak and Seri Lueamrung.

4.1.3 Period 3: Influence of ASEAN on Thai Identity from 1987 to 2000

Performances used Western movements for Thai stories by taking conventional Thai dance identity and combining it with modern Western dance. New techniques were chosen for live performances. During this period, government policy and the ASEAN vision, mission and agreement played a role in creative design. Conferences and agreements regarding the cooperation of ASEAN countries led to the launch of the ASEAN Dance Festival, which has subsequently been held many times. The festival has included academic meetings, training and performances by various countries attending the dance meeting. This has caused development in the use of new dance and presentation techniques, including cultural exchange. In turn, these developments caused the creation of Thai contemporary dance that clearly revealed Thai identity. Artists with important roles in this period were Bancha Suvannanonda, Narapong Charassri, Vararom Pachimsawat, Manop Meejamrat's Pattarawadee Theater, Peeramon Chomdhavat, Pichet Klunchun and Julachat Aranyanak.

\subsubsection{Period 4: Creation of Unique and Individual Concepts from 2001 to the Present Day}

Performances combine modern dance, Western contemporary dance and Thai stories. It is popular to use accounts of everyday stories and social problems together with stories from Thai literature. The signature postures, music and costumes are Thai. Live performance techniques are adopted and modern technology is used in the design process. New independent styles are performed in terms of ideas and limits, while choreographers strive for originality in the creation process to present individually different performances. The artists with an important role in this period are Manop Meejamrat, Pichet Klunchun and Thongchai Hannarong. 


\subsection{Concepts of Thai Contemporary Dance}

There are three concepts of Thai contemporary dance: a) presentation and performance of stories from popular literature that contain abstract themes, such as belief, religion and love; b) presentation of stories from experience or current events; and c) original artistic ideas that are used to create an individual identity for presentation in creative work.

\subsection{Basic Dance Choreography in the Style of Thai Contemporary Dance}

The basic dance choreography and steps of creative choreographic design in the style of Thai contemporary dance must have four factors, which are a) input-the selection of different materials to be used in the performance, aim, concept, inspiration and opportunity, story, script, performers, music, costume and decorations, props, background, stage, lighting, special techniques and others; b) process-the entire process stage from searching for story concepts and creation of the story to the conclusion of the process and pre-performance rehearsals; c) output-an act or story performed to clarify abstract material, which must express feeling and be emotive; d) outcome-benefit from viewing the performance. The objectives of organizing Thai contemporary dance, aside from entertainment, are to show the creative artistic design capabilities of the choreographers to relate to the country and further academic progress.

Contemporary Thai dance uses combinations to create innovations for the benefit of conservation and development. It presents dance in a new style by creating new regulations, design methods and components from the past and from the present to be used in combination with basic creative design, by reduction, increase, role reversal or reworking for new arrangements. This includes the creation of new concepts, which could use a single or a variety of methods, the creation of new regulations or spread combination and single or multiple art styles. Successful output depends on the individual technique of the artist. Confusing, overly complex designs with unclear meanings cause misunderstanding and discomfort among the audiences. It is popular for contemporary dance to be innovative in its creative design concepts. The creation of Thai contemporary dance causes knowledge, understanding or misunderstanding, entertainment or humdrum. In answer to social problems, artistic product and value are created, as well as various aspects of beauty and aesthetics. Work is created and transmitted to cause the conservation of Thai art culture and the fulfillment of artist requirements.

\section{Discussion}

Thai contemporary dance must have form and characteristics that are at least partially new and must be clearly differentiated as a highly developed form of traditional dance style or classic performance, such as ballet drama, jazz, khon, nang yai (grand shadow play), ram wong (Thai circle dance) and indigenous or folk dance. However, Thai contemporary dance can be used to perform romantic ballet with the same arrangement, costumes (such as long skirts and bare feet), music and postures. Contemporary form and characteristics that occur in Thailand and are a product of the work of Thai nationals have been adapted according to the period and artistic evolution, whether it is a work of art, architecture, music, literature or dance. Although Thailand has had communication with other countries since the time of King Naresuan (reign: 1590-1605), the Western styles could first be clearly seen during the reign of King Mongkut (Rama IV) (reign: 1851-1868) when art and artists from foreign countries entered Thailand, influenced Thai culture and caused art of all varieties, including dance, to develop and continuously change. However, dance that was a combination of foreign arts became its own new style and was revealed during the reign of current Thai monarch King Bhumibol Adulyadej. Due to the requirements of a large performance cast and high budgets, some styles were performed infrequently and disappeared. This means that modern performances tend to be of a similar style and use smaller casts. The abilities of the performers and the materials are various, which enables the presentation to incorporate many different art forms, such as drawings of dance, musical performance, singing and drama. Technology is integrated into the shows.

\subsection{Form and Prominent Characteristics in the Creative Design of Thai Contemporary Dance Artists}

In the past, design concepts, inspiration, techniques chosen by the artists for choreographic design and the creative process of the artist were important factors in the creative artistic design of Thai contemporary dance. This was the case regardless of appearance, institution, family, status, dependents, education, experience, social environment and problems. These acted as variables and important motivational strengths in propulsion of artistic desires and are the reasons why the artists seek opportunities to further their experience in order to be accepted by society.

\subsection{Management of Artistic Components in Thai Contemporary Dance}

The management of creative design components of Thai contemporary dance choreography is similar to the general management of components in art and includes line, form, color, texture, tempo, rhythm and space. This 
is to benefit the creative design process, so that it uses the knowledge of choreographers. As it is popular to use these components, choreographers of Thai contemporary dance are given an artistic advantage. The characteristics of the management are popular in a variety of formats, which have both symmetrical balance and asymmetrical balance. However, there will be clear aims or focus points for the things and feelings that the choreographer wants to present or convey to the thoughts and eyes of the audience by using body gestures, movement and a variety of components as tools and parts of the presentation procedure. The characteristics of ideas that the Thai contemporary dance choreographers popularly use are collective, creative and communicative and, although some artists will use cognitive thought processes, many choreographers will not have a reason for their thought processes in the creation of new and climactic work.

In the creation of Thai contemporary dance, choreographers favored work with some traces of Thai identity. This was revealed in the performance by inclusion of stories, morals, beliefs, perspectives, customs, conventions and Thai lifestyle that reflects society, culture or current events, from the simplest to the most complex. These were present in the view of the material, the format, the outline of the story and the presentation in order to show the nature of the work as contemporary, trendy and international. This was in order to meet the needs of the people in a modern global society where everything has become more hurried, the separation of regulations, the use of modern technology, communications, lifestyle changes, economy, society and needs that change according to time. Therefore, the artists must develop and create in order to strengthen and beautify the work in response to these changes, the needs of the audience and the objectives of organizing the performance. In this way the artists and the art form can survive. Even though the art has aesthetic and mental value, there is no way for it to exist if there is no audience.

Success of performance stems from the creation of work that corresponds to the skill of the performers, is meticulous, obeys a code of conduct and is intensively rehearsed. Performers must practice so that they have strength and seriousness in their work, perform rigorously and incorporate a variety of interesting and beautiful dance postures. Artists will then perform well and in harmony and produce an impressive show.

One reason for choreographers to create dramas and dance performance by using Thai stories is that foreign and international stories come from societies and lifestyles that are significantly different from the East. This means that they are difficult for Eastern people to understand and it is especially difficult to find choreographers with the required knowledge and understanding of values, lifestyles, ideas, customs, traditions and history in the story. This makes the stories difficult to reenact and limits their success and acceptance by the audience. It is thus difficult for Thai people to understand foreign stories and for performers to recreate them. Therefore, Thai contemporary dance enables choreographers to tell stories relevant to the Thai audience without forcing reliance on Thai-only forms of expression. Thus it becomes a wonderful synthesis of East and West instead of something that does not work for its target audience.

\subsection{Creative Method of Artists}

It is natural for most artists to begin thinking about the movements from dance styles in which they are skilled rather than those in which they are not skilled. Even though the eventual postures are different from the original formats, there remain style traces of the founding skill and preference of the artist. An example is in the performances of graduates from the fine arts department of Chiang Mai University, who favor the use of Lanna dance postures combined with different arts, Lanna music, costumes, props and performance components. They take these styles and create new designs, which is a form of Thai dance known as contemporary Lanna dance.

The concepts of Thai contemporary dance came from two characteristics, which were the presentation of stories or acts from popular literature and the presentation of abstract themes from experience and thoughts about the creator. This second concept may have occurred because the topic was well known to the individual creator and the creator could best relate and accurately relay their feelings and desires. From this, research was conducted to create theories and reasons to be used in the composition of work in order to increase the depth of meaning and quality of the work. Furthermore it had a higher value for the creation of work, particularly that which was about the individual. For example, when the artist feels unfairly treated by society, they will write a piece that reflects the negatives of the society. Those artists with no bias towards society will create work that is balanced, highlighting both the positives and the negatives. Those artists with a good creative ability and concept will allow the audience to see the consequences of negative actions and encourage them to make their own decisions.

Many times, the creation of choreographers' work is able to benefit the audience, performers and the individual choreographers, such as helping with requited and unrequited love. In the end, when the artist has found data related to love and its results to incorporate into the production, they may think that love is not only for young couples but there is also the pure love of parents, love of the nation and territory and love of pets. 
It is not necessary for work created in Thai contemporary dance to be a performance that tells a story. The choreographer may create a plot from abstract concepts to be used in the results of their work. It is not usually popular for Thai dance choreographers to use a single style of dance and performers on the stage to reenact stories of modern Thai society. Rather, they use a variety of components to create a story or act to present using a variety of dance techniques that are suitable for the presentation of the choreographers' needs, thus creating Thai contemporary dance work.

Contemporary dance is a form of modern dance that has a creative identity. Some characteristics are formats that have already occurred for a long time but others continuously change because humans in the world live in a variety of different ways. Thai contemporary dance is an art full of meaning and reflects the changes to societies with customs and the adoption of these customs by other societies. This creates a larger sea of differences, good and bad. It is impossible to say what is good and what is bad because this is a decision for the individual, based on their likes and dislikes. Modern society is a place of knowledge and constant learning. It is necessary to continually seek new knowledge to keep up to date with trends and understand adaptations. The creation of many different types of work comes from research and is an experiment for the trial of new techniques and components when the choreographer does not wish to follow other artists. This creates an individual artistic identity. Some artists have their own unique style and sometimes the choreographers do not wish to follow their own style, so they generate new concepts of Thai contemporary dance, follow foreign trends or set new trends for foreigners to follow by taking their own basic theories, completely and roughly. They use adapted methods to create new roots and achieve success fast but sometimes neglect the quality of the work. Alternatively they use their own established roots, which require a long time for practice and development but ensure a highly finished product that is more likely to be accepted and achieve continued success. The prominent characteristics of Thai contemporary dance come from the knowledge and ability in which each artist is skilled. Consequently, the results of the work depend on the experience of the ensemble. Even though performers are Thai, the techniques and dance styles in which they are experts come from ballet more often than other dance styles. When this is compared to classic dance or traditional customs, Thai contemporary dance is more visible than before and audiences have a greater opportunity of witnessing the performances in modern society than before. Thai contemporary dance is a living art that can be used in everyday society by all classes and is not restricted by social status as in the past. Nowadays, there are spaces, stages and educational institutions that have specifically and continually increased the acceptance of this art form.

Thai contemporary dance is a new form of performance that came to Thailand when artists either viewed Western styles or returned home from visiting other countries and tried to incorporate them into their work. Initially there were no domestic experts in the art form, so the choice was either to employ foreign choreographers or allow the Thai choreographers an opportunity to learn their trade. This does not mean that the art was copied, which would have been against the code of ethics for the artists, but rather was used as an inspiration and example. They may have used the same techniques and music but the Thai choreographers incorporated their own skills and experience, concepts, creative processes, reconstruction, production, correction and other components. These inclusions created a new art form with quality and value for aesthetics and beauty.

It has been said that art is ever-changing, especially creative art of all forms. This is because the artists change, as do the stories, dance techniques, steps and movement, presentation or production, concepts, music styles or songs of the artists, costumes, props and components. The artists will also change the imitations of their own style and the style of others. This is because it is not popular to reproduce performances in modern contemporary society. If performances are not adapted, the audiences will be bored easily and their wishes for newly developed performances from their favorite artists and performers will not be fulfilled. The researchers found that many performers repeat their work. However, although the names are the same, it is common for adaptations to be made, apart from those performances which the choreographer is confident are perfect and still in demand with audiences and sponsors. If demand remains, it is evidence of the popularity and success of the choreographer and will become a stronger part of their identity.

Thai contemporary dance performance, when analyzed alongside the artistic theory of expression, usually comes from choreographers and reflects their personality, the transmission of internal feelings or may allow them to express the things on their mind. This is thus a performance with an intention; it is artistic performance with aims and individual value. The choreographer will place importance on different forms of media to broadcast emotions and give importance to the cohesiveness of moods and feelings. Sometimes, the stories will include the emotions of the choreographers themselves in order to express them through the media of the performance. 
As Thai contemporary dance is an art form that uses steps and movement of the body as important tools of transmission, most performances will show a variety of signatures and shapes in the body structure, the lines of the arrangement and the use of the body in different positions.

\subsection{Characteristics of Thai Contemporary Dance}

Performances that emphasize beauty and entertainment, where the audiences just experience the performance and do not need to think about it, mostly come from a mixture of styles, are well-laid out and contain beautiful postures. The performers have good bodies, are well-proportioned, attractive and dance beautifully. The arrangement is balanced, music is melodic, and costumes are elegant and appropriate for the performance, including the background, stage, beautiful color, lighting and sound.

Performances that emphasize the communication of ideas, conceptual dance and presentation of dance will be wider in their perspective and the choreographer is able to think outside the boundaries of the performance. In viewing this type of performance, the audience must think and try to understand the ideas that the choreographer wished to present and how clear they are. This style of performance has no fixed regulations or level of sufficiency and when it has been seen, it is not necessary for the audience to have identical opinions and it is not necessary for the audience to always like or dislike the work. Some people may be enthusiastic about the work, while others may dislike it. However, for the artist to be considered successful, the audience must understand the creative objectives of performance. For this reason, the choreographer must be cautious in the production of the performance and must conduct thorough research from believable and socially accepted data or they must be an expert in the stories they are reenacting.

For the thoughts and creation of Thai dance that includes Western styles, the performers and the choreographers must possess knowledge and expertise in dance. They must have excellent skill, experience and must be accepted by the art and dance communities. When they have created their work, there will be no problem of resistance as Thai dance culture and the cultures of almost all countries in Asia respect and believe the work of those people with age, experience and wisdom. However, in Western culture it is not necessary for the choreographer to be a good dancer or possess high technical skill. Regardless, they must be intelligent in the selection or creation of different ideas and must lay out their performance well, in terms of creation, ideas and imagination. The choreographer must be brave enough to use different and unique new techniques, which is the essence of a Thai contemporary dance piece.

The characteristics of Thai contemporary dance of the present day are the same as the characteristics of beauty in the five primary aesthetic forms of Max Dessoir, a German philosopher: the beautiful, the sublime, the tragic, the ugly, and the comic. This approach fits with the concepts of modernism that view beauty as a new incident and this becomes a connecting concept and tries to correct the problems of previous theories by stating that beauty is something that is established rather than a relationship between people and objects. This is also true for the postmodernist school, who view the real and the apparent as having separate characteristics, tangible and intangible, by considering form and function. According to these views, the researchers found that choreographers create work that is both structured and unstructured and, in almost all cases, there will be pre-composition, improvisation and various dance techniques. Improvisation - creating on the spur of the moment - is an indispensable and exciting part of dance experience. For the dancer and choreographer, movement improvisation is a prelude to choreography. It is also a tool for developing an individual's performing sensitivity and a means of discovering the body's natural movement style (Cheney, 1989, p.73).

Thai contemporary dance choreographers are highly individualistic, have expectations for their performances and prefer to be independent. They like to create performances outside customs and traditions or social regulations as much as they are able and take risks as far as they can without harming their original intentions. Therefore, people wishing to create or break from regulations in any story must study and research well before undertaking any work. When the format has been outlined, they should invite experts to view the performance and help internally evaluate its value and accuracy before performing to the public. Thai contemporary dance does not hold fast to a strict order of design, creation, presentation and dance components. This may sometimes make the performance seem unreal. At the present time, there is disagreement over whether there should be defined limits to Thai contemporary dance and whether certain performances are outside those limits.

Thai contemporary dance is similar to all art forms in its need for three important factors, which are choreographer, audience and inheritor. The choreographer is the person who defines the objectives, reasons and outline of the work. They decide whether the work will be a reproduction or new. The audience is the group of people who view the work. The knowledge and experience of society and the value and beauty of the work will 
determine the level of performance popularity among the members of the audience. The inheritor is the person who inherits, maintains and studies the work.

The adaptations or dynamism of Thai contemporary dance depend on social conditions, the economy, politics and industry, as well as the important factors of choreographer, audience and inheritor. These things make Thai dance creation difficult as it is unknown what obstacles will be encountered. The choreographers must constantly invent to develop or establish individual creative concepts and methods that are accepted in the future.

\section{References}

Adshead, J., Briginshaw, V. A., Hodgens, P., \& Huxley, M. (1988). Dance Analysis: Theory and practice. Edited by Janet Adshead, London: Dance Books Ltd.

Boonpeng, S. (2006). Documents for teaching choreography 1. Teaching material.

Cheney, G. (1975). Basic Concepts in Modern Dance: A Creative Approach (3rd ed.). New Jersey: Princeton Book Company.

Dilgawanit, M. (2000). Dance and drama in Asia. Bangkok: Thammasat University Press.

Du Pont, B., \& Schlaich, J. (n. d.). Dance: The Art of Production (3rd ed.). New Jersey: Princeton Book Company.

Ellfeldt, L. (1971). A Primer for Choreographers. California: The National Press.

Gonzales, J. (2004). Choreography: A Malaysian Perspective. Kuala Lumpur: Ministry of Arts, Culture and Heritage.

Hawkins, A. M. (1991). Moving from Within: A New Method for Dance Making. Chicago: A Cappella Books.

Horst, L., \& Russell, C. (1987). Modern Dance Forms: In relation to the other modern Arts. New Jersey: Princeton Book Company.

Humphrey, D. (1959). The Art of Making Dances. New York: Grove Press.

Kamson, O. (2008). Viewing Artwork: Research program and critique. Bangkok: Chomnat Print.

Minton, S. C. (1997). Choreography: A Basic Approach Using Improvisation (2nd ed.). United States: Human Kinetics.

Nagavejara, C., (Project Leader) \& Lake, M. (Eds.). (2005). Criticism as Cross-Cultural Encounter. Research Project" Critism as an Intellectual Force in Contemporary Society", Bangkok, Chommanad Press.

Naraphong, C. (2007). Narai Avatara Performing the Thai Ramayana in the Modern World. Bangkok: Amarin Printing.

Nor, M. A. M. (2000). Asian Dance: Voice of the Millennium. Asia Pacific Dance Research Society, Cultural Centre, University of Malaya: Ministry of Culture Arts and Heritage.

Nor, M. A. M. (2003). Diversity in Motion. Kuala Lumpur: Cultural Centre, University of Malaya.

Nor, M. A. M. (2007). Creating Dance in Asia Pacific: Dialogues in Dance Discourse. World Dance Alliance, Asia, Cultural Centre, University of Malaya: Ministry of Culture, Arts and Heritage.

Pong, C. S. (1998). ASEAN Dance Symposium at the 4th ASEAN Dance Festival. Singapore.

Rodjanasuksomboon, A. (2006). Concepts and theories of new style Lanna dance. Chulalongkorn University: Chulalongkorn University Press.

Rungrueangsadee, G. (2004). Mom Rajawongse (M. R.) Kukrit Pramoj and Conservation of Thai Culture: Case study of Thammasat Kone. Bangkok: Ramkamhaeng University.

Rutnin, M. M. (1996). Dance, Drama, and Theatre in Thailand: The Process of Development and Modernization. Chiang Mai: Silk Worm Books.

Virulrak, S. (2001). Dance periscope. Bangkok: Hongpapsuwan Publishers.

Wetsurak, S. (2004). Dance principles of Mrs. Paew. Sanitwong Senee, Chulalongkorn University: Chulalongkorn University Press.

\section{Copyrights}

Copyright for this article is retained by the author(s), with first publication rights granted to the journal.

This is an open-access article distributed under the terms and conditions of the Creative Commons Attribution license (http://creativecommons.org/licenses/by/3.0/). 